\title{
Analysis on the Influence of High School Mathematics Course Reform on College Mathematics Teachers
}

\author{
Shufeng Li \\ College of Science, Mudanjiang Normal University, \\ Mudanjiang, 157011, China
}

\begin{abstract}
Nowadays, with continuously deepening reform of the education field, college mathematics teachers should have a clear understanding of high school mathematics curriculum reform, combine actual conditions of high school mathematics curriculum reform, make proper adjustment to their teaching ideas, update the structure of knowledge, specify the value of college mathematics curriculum, and create conditions for teaching of mathematics knowledge in a more reasonable, more scientific and more effective way. To this end, the author in this paper discussed the influence of high school curriculum reform on college teachers based on the influence of high school mathematics reform on the optimization of teaching contents of college mathematics.
\end{abstract}

Key words: high school mathematics, course reform, university, mathematics teacher

\section{Introduction:}

In the $21^{\text {st }}$ century, various countries in the world are confronted with economic competition and technical revolution. Under such circumstances, Chinese government thought that continuously deepening the educational reform and positively cultivating practical talents was a key factor to promote sustainable development of China. In the $21^{\text {st }}$ century, therefore, China's educational reform becomes an inevitable trend. As the focus of curriculum reform, high school mathematics curriculum reform has great influence on both the teaching of high school mathematics and the teaching of college mathematics, especially for college mathematics teachers. High school mathematics curriculum reform is like a "sharp change" process for college mathematics teachers, including changes in teaching concept, teaching approach and teaching role. Based on above contents, the author made a detailed analysis and discussion on the influence of high school mathematics curriculum reform on college mathematics teachers. 


\section{Influence of high school mathematics curriculum reform on optimization of teaching contents of college mathematics}

(I) Changes in college mathematics education under high school mathematics curriculum reform

In April, 2003, the Ministry of Education issued Standard for Mathematics Curriculum in Ordinary Senior High Schools. In terms of content and knowledge structure, new curriculum standard for new curriculum standard had great changes when compared with traditional mathematic textbooks no matter in curriculum idea or curriculum framework and curriculum content. Such changes are unparalleled against previous mathematics curriculum reforms. During high school mathematics curriculum reform, college mathematics teaching is influenced to some extent, resulting in somewhat changes in college mathematics education. At present, most universities in China are positively performing educational reform. As a result, curriculums in different forms or types were created, such as excellent courses. Viewed from the overall situation of China's college mathematics course teaching, however, our college mathematics teaching is influenced by high school mathematics curriculum reform, basically reflecting in fine adjustment to teaching material. Basically, there is no any change in model of teaching, teaching approach and others alike.

(II) Issues of college mathematics teaching requiring settlement under high school mathematics curriculum reform

1 Optimize and adjust the contents of college mathematics according to new curriculum standards for high school mathematics

In the high school mathematics curriculum reform, some teaching contents in the original mathematics course were deleted. At the same time, some new contents were added, promoting the teaching of high school mathematics curriculum to be more basic and closer to students. Under the circumstance of high school mathematics curriculum reform, the teaching of college English should be properly optimized and adjusted according to actual conditions of high school mathematics curriculum reform, promoting the teaching of college mathematics to effectively link up with high school mathematics and drive better development of students.

2 Deepen the teaching philosophy of "active and brave in exploration"

The teaching philosophy of "active and brave in exploration" is advocated in the high school mathematics curriculum reform. As cradles for cultivation of students, 
colleges and universities should deepen the teaching philosophy of "active and brave in exploration” in the process of developing teaching activities of college mathematics, promote teaching activities of college mathematics to be based on actual conditions of students, plan teaching activities in a scientific and reasonable way, teach students mathematics knowledge, cultivate students' innovation consciousness, train their practice ability, enhance their spirit to making explorations and create conditions for the promotion of all-round development of students.

3 Cultivate students' ability of logic thinking

Traditional high school mathematic textbooks laid emphasis on systematic knowledge as well as students' solid basic knowledge, adept basic skills and spirits of hardworking. After the high school mathematics curriculum reform, however, the double-base basis of mathematics was weakened. Under this circumstance, we should combine theorem analysis, demonstration and other contents to cultivate the rigorous and rational thinking ability of students in the process of college teaching, so as to meet needs of students for pioneering and innovation in the future learning, work and research. Certainly, it is uneasy to realize effective cultivation of students' ability of logic thinking by the teaching of college mathematics. We should develop from mathematical knowledge mastered by students, educate the students step by step, and promote students to gradually enhance their ability of logic thinking in long-term guidance.

\section{Influence of high school mathematics curriculum reform on college mathematics teachers}

Based on above influence of the high school mathematics curriculum reform on optimization of the teaching of college mathematics, college mathematics teachers, as dominant roles in the teaching of college mathematics, teachers are also influenced to some extent, resulting in "sharp changes" of college mathematics teachers. The influence of high school mathematics curriculum reform on college mathematics teachers is mainly reflected in the following aspects:

(I) Establish advanced educational ideas compatible with new curriculums

The most essential change of high school mathematics curriculum reform lies on changes in educational idea. Traditional high school mathematics teaching laid emphasis on the cultivation of students' knowledge level. However, this high school mathematics curriculum reform proposed new educational ideas compatible with 
the times, national condition and education on the basis of globalization of contemporary economy, cultural diversification and socialization, giving full expression to the overall tendency of educational development and reflecting people's longing and pursuit for a beautiful life. Based on above contents, college mathematics teachers should clearly recognize that the high school mathematics curriculum reform is not a simple teaching curriculum reform. Instead, it is renewal of educational idea and change in talent cultivation mode. Viewed from the overall situation of the high school mathematics curriculum reform, changes took place in high school mathematics curriculum structure, curriculum standard, teaching idea and other aspects. Under a brand new reform for high school mathematics curriculum, teaching ideas of college mathematics teachers are influenced first.

For a long time, college mathematics teachers laid much emphasis on teaching materials and teaching programs in terms of mathematics teaching as well as all-round and detailed development of teaching according to mathematics textbooks. On the basis of the high school mathematics curriculum reform, however, college mathematics teachers should first abandon traditional teaching ideas, have the consciousness of students, courses, openness and issues, and create conditions for scientific and reasonable teaching. The transformation of teaching ideas of college mathematics teachers: (1) lay emphasis on all things for students' development; in the process of developing college mathematics teaching activities, first understand students' learning experiences, master their learning ability, interests, hobbies and learning difficulties, make reasonable plans for mathematics teaching activities, and promote teaching activities to face and be closer to students, so as to motivate their interests; (2) under the influence of the high school mathematics curriculum reform, college mathematics teachers have clear cognition of the essence of modern mathematics and the value of mathematics course. On this basis, college mathematics teachers should make scientific and reasonable adjustment to mathematics teaching activities; (3) to promote college mathematics to be effectively link up with high school mathematics knowledge, college mathematics teachers should guide and teach students step by step, and promote them to gradually understand and master mathematics knowledge and skills.

(II) Update knowledge structure and adapt to students' development Oates Bell, a famous American educational psychologist, ever said that "if I was 
asked to reduce educational psychology into one sentence, then I should express all things in a word: the only important factor influencing studies is to explore for what students have already known and then teach on this basis”. He fully explained that original knowledge and experience of students was the starting point of all teaching activities. On this basis and in the high school mathematics curriculum reform at present, the teaching of college mathematics should begin with high school mathematics knowledge mastered by students and reasonably teach students, so as to promote them to really understand and master college mathematics knowledge. For scientific and reasonable teaching of students, college mathematics teachers should update the knowledge structure, effectively link up college mathematics course teaching with high school mathematics knowledge, and promote the teaching of college mathematics to adapt to students' development based on the high school mathematics curriculum reform. In terms of renewal of knowledge structure of college mathematics teachers, they should first understand changes in high school mathematics curriculum and understand the contents of changes in high school mathematics curriculum through a comparison of mathematics curriculum contents between old and new textbooks. Based on specified contents of changes in high school mathematics curriculum, college mathematics teachers should fully consider the change orientation of college mathematics curriculum. Moreover, college mathematics teachers should make it detailed for changes in teaching of calculus, advanced algebra and probability statistics in terms of changes in college mathematics curriculum, so as to effectively link up college mathematics teaching activities with knowledge level of students. Finally, college mathematics teachers should recognize and understand applicability and humanistic value of mathematics, begin with function and significance of mathematics, make proper adjustment and renewal to their knowledge structure, and promote them to adapt to constantly changing teaching activities, so as to teach students and serve educational business in a better way.

(III) Emphasize curriculum values of college mathematics in the teaching practice Curriculum standards for high school mathematics gave recapitulative, comprehensive and high evaluation to the value of mathematics course, mainly including basic \& tool features, application value and humanistic value of mathematics. Colleges and universities are served as cradles for the cultivation of high-quality talents. In the process of teaching students, teachers should give full 
play to scientific value of mathematics, and promote students to really master disciplinary knowledge. College mathematics teachers should make continuous exploration and research for the value of college mathematics course on the basis of the high school mathematics curriculum reform, so as to reasonably reveal values of mathematics in basic, tool, application and education, clearly realize importance and significance of college mathematics teaching, positively devote into teaching activities of college mathematics and serve schools, the society and the nation in a better way.

Under the high school mathematics curriculum reform, how college mathematics teachers can emphasize curriculum values of college mathematics in the teaching practice?

First of all, mathematics teachers should fully realize that mathematics is one of tools for people to know the nature. Upon development and research of mathematics for thousand of years, formed theories were obtained from people's knowing and summarizing the nature. In the practice of mathematics, college mathematics teachers should effectively combine mathematics with the nature, verify mathematic theories and recognize the essence of mathematics.

Then, mathematics teachers should fully recognize mathematics is essential to human development. Under the high school mathematics curriculum reform, college mathematics teachers should start with teaching ideas of high school mathematics, understand the significance of developing college mathematics and specify political attitude and materialism thoughts of college mathematics.

Finally, mathematics teachers should fully cognize that mathematics is an important part of human culture. Through the ages, people utilized mathematics to create, store, pass and develop human culture. In the entire process of human culture, mathematics played this important role. In a sense, mathematical culture accomplishment can embody conducts and morality of a person. Therefore, college mathematics teachers should really understand mathematics and improve their cognition of mathematics course value in the mathematics practice.

(IV) College mathematics teachers should become learners, researchers and even cooperator.

One of very important philosophies of the high school mathematics curriculum reform is to cultivate students to learn and set up the thought of lifelong learning. With economic globalization at present, competitions between countries have 
already transformed into talent competition. To realize the ambitious goal of sustainable development, China proposed the philosophy of "lifelong learning”. Therefore, both students and teachers should take learning as on part of their life and cultivate a good habit of learning in the times of lifelong learning.

In the times of lifelong learning, college mathematics teachers should play the part of learners, researchers and cooperators in the teaching process. The purpose of acting as learners is to advance with the times, continuously update knowledge, thought and concept, and promote them to get full development in the post. The purpose of acting as researchers is to cultivate talents for the nation. Under the high school mathematics curriculum reform, teaching activities of college mathematics should be researched, with expectations to face and be closers to students for developed teaching activities, and promote students to master mathematics knowledge. The purpose of acting as cooperators is to establish positive partnership with peers, establish a kind of new platform to promote cooperation, experience sharing and improvement to educational level between teachers, enhance cooperation with students on class and in classroom, and jointly structure knowledge.

\section{Conclusion:}

As the focus of curriculum reform in the education field, the high school mathematics curriculum reform influences both high school mathematics teaching and teaching activities of college mathematics, resulting in some changes in teaching contents of college mathematics. College mathematics teachers went though sharp changes. Actually, college mathematics teachers had sharp changes under the influence from the high school mathematics curriculum reform: establish advanced educational ideas compatible with new courses, update knowledge structure, adapt to students' development, and emphasize curriculum values of college mathematics in the teaching practice. College mathematics teachers should become learners, researchers and even cooperator. I believe that college mathematics teachers will have better performance in the teaching of college mathematics and create conditions for the cultivation of more talents after such sharp changes.

\section{Acknowledgments}

This paper is a general youth project of Mudanjiang Normal 


\section{University (QY201318).}

\section{References:}

[1] Pi Lei, Discussion on the Influence of High School Mathematics Course Reform on College Mathematics Teachers [J], Journal of Xinxiang Education College, 2008 (01);

[2] Wang Zhichao and Chen Xiaojiao, Connection Problem of Middle School Mathematics and College Mathematics [J], Theory Horizon, 2005 (06);

[3] Shi Rongxin, Adaption to Course Reform of Elementary Education and Reform of Normal Education Course [A], collected papers of 2002 excellent normal education research results of Shandong Society of Normal Education [C], 2002;

[4] Li Jiahou, How Educational Technology to Welcome New Curriculum Reform of Basic Education - for Entrustment of Our Nation [A], collected papers of 2002 annual meeting of China Association for Educational Technology [C], 2002;

[5] Zhang Jing, Discussion on the Transitional Issue of Teaching from High School

to College Mathematics [J], Journal of University of Shanghai for Science and Technology(Social Science), 2005 (04). 